\title{
LA AZAROSA REGULACIÓN DEL IMPUESTO SOBRE EL INCREMENTO DE VALOR DE LOS TERRENOS DE NATURALEZA URBANA Y LOS LÍMITES CONSTITUCIONALES A LA FALTA DE CONSIDERACIÓN LEGISLATIVA DE LA REALIDAD DE LAS PLUSVALÍAS EN EL ÁMBITO MUNICIPAL ${ }^{1}$
}

\author{
María Amparo Grau Ruiz \\ Departamento de Derecho \\ Financiero y Tributario \\ Facultad de Derecho. \\ Universidad Complutense de Madrid \\ grauruiz@ucm.es
}

\section{INTRODUCCIÓN}

El Impuesto sobre el Incremento de Valor de los Terrenos de Naturaleza Urbana (IIVTNU), desde la Ley 39/1988, de 28 de diciembre, Reguladora de las Haciendas Locales (LRHL), prevé la cuantificación de la obligación tributaria de forma objetiva. La Ley 51/2002, de 27 de diciembre, al modificar el art. 107 LRHL, hizo desaparecer el término «real» que adjetivaba al incremento del valor de los terrenos, que constituye la base imponible. La doctrina ha criticado reiteradamente la posible vulneración, en algunos casos, del principio constitucional de capacidad económica, fundamentalmente en la medida en que queda desvinculado el tributo de la capacidad económica real del sujeto pasivo (por gravarse las plusvalías puestas de manifiesto con ocasión de la transmisión de terrenos urbanos, calculadas a tanto alzado) ${ }^{2}$.

${ }^{1}$ IP Proyecto CertificaRSE «Efectos jurídico-financieros y control del impacto social para el desarrollo sostenible: el papel de las certificaciones en las inversiones y la contratación pública» (DER2015-65374-R MINECO-FEDER).

${ }^{2}$ M. Á. Martínez Lago, «Impuestos locales» (capítulo XIII), en AAVV, Sistema fiscal español: Impuestos estatales, autonómicos y locales, Madrid, Iustel, 2016, pp. 459 y ss.; G. Orón Moratal, «La base imponible del Impuesto sobre el Incremento de Valor de los 
Tras una etapa de crisis económica, en la que la conflictividad ha alcanzado extremos inesperados, dadas las injusticias que ha provocado una norma elaborada pensando en otra coyuntura, parece que finalmente el Tribunal Constitucional ha definido ciertos límites a la actuación del legislador.

Quedan pendientes de resolución todavía algunas cuestiones importantes, tales como las discrepancias con pronunciamientos previos de otros órganos jurisdiccionales con competencia territorial limitada, o la evidente necesidad de aclarar el sentido de una previsible reforma de la normativa estatal en un futuro inmediato.

\section{LA OBLIGADA POSICIÓN RÍGIDA DE LA ADMINISTRACIÓN TRIBUTARIA Y LA CONSIGUIENTE CONFLICTIVIDAD}

En contestaciones a consultas vinculantes, la Subdirección General de Tributos Locales ha señalado que, en el momento del devengo del IIVT$\mathrm{NU}$, el valor del terreno es el que tenga determinado en dicho momento a efectos del IBI: el catastral en la fecha de la transmisión de la propiedad, sin tener en cuenta el valor catastral en el momento de la adquisición del terreno, o los valores de compra y venta del mismo. Ha recordado que tampoco toma la Ley en consideración, para el cálculo de la base imponible, el precio de venta limitado administrativamente para una vivienda calificada de protección pública de precio limitado 3 . Por otro lado, los ayuntamientos pueden establecer una reducción en la base imponible, durante los cinco primeros años de efectividad de los nuevos valores catastrales, sólo si se modifican los valores catastrales como consecuencia de un procedimiento de valoración colectiva de carácter general ${ }^{4}$.

Terrenos de Naturaleza Urbana», en Estudios y Comentarios Legislativos (BIB 2011 5859), Civitas; F. Vilches García, «El Impuesto sobre el Incremento de Valor de los Terrenos de Naturaleza Urbana. Incidencia de la depreciación del suelo en la cuantificación de la base imponible», Aranzadi Doctrinal, núm. 2 (2014), pp. 65-80, y J. CALVo VérgEZ, «La incidencia de la condición urbanística del terreno en la cuantificación del Impuesto sobre el Incremento de Valor de los Terrenos de Naturaleza Urbana: principales cuestiones conflictivas», Quincena Fiscal, núm. 13 (2012), pp. 21-57.

${ }^{3}$ Consulta Vinculante V3067-13, de 15 de octubre de 2013, de la Subdirección General de Tributos Locales.

${ }^{4}$ Consulta Vinculante V0291-14, de 6 de febrero de 2014, de la Subdirección General de Tributos Locales. 
Se ha subrayado que, en el caso de que se transmita un inmueble por un precio inferior al de adquisición, el impuesto somete a tributación una plusvalía cuantificada de forma objetiva, en función del número de años transcurridos entre la adquisición y la transmisión del terreno, hasta un máximo de veinte. Se ha reconocido sin ambages que el porcentaje de incremento máximo anual constituye una regla objetiva disociada de la realidad, que puede ser inferior o superior al incremento real del terreno ${ }^{5}$.

No se ha admitido que se produzca doble tributación con respecto a las liquidaciones satisfechas por anteriores propietarios de un bien inmueble, cuando el impuesto se ha liquidado en cada caso atendiendo al valor del terreno en la respectiva fecha de devengo, teniendo en cuenta, en cada una de las liquidaciones, el número de años a lo largo de los cuales se pone de manifiesto el incremento de valor (esto es, entre las distintas fechas de adquisición y transmisión del bien inmueble) ${ }^{6}$.

Esta posición interpretativa, mantenida de manera firme, ha generado un elevado número de litigios en torno a las frecuentes transmisiones con pérdidas acontecidas en los últimos años, en particular, tras la explosión de la burbuja inmobiliaria ${ }^{7}$. Esta situación ha dado lugar a variados plan-

5 Consulta Vinculante V0153-14, de 23 de enero de 2014, de la Subdirección General de Tributos. El Ayuntamiento competente, en la ordenanza fiscal reguladora del impuesto, tenía establecida la reducción del art. 107.3 en el porcentaje del 40 por 100, que se aplicó en la liquidación practicada.

${ }^{6}$ Consulta General 0003-14, de 27 de enero de 2014, de la Subdirección General de Tributos Locales.

7 Buena muestra de ello son las abundantes cuestiones de inconstitucionalidad admitidas a trámite, tal como se recogen en el «Especial IIVTNU - Plusvalía Municipal» preparado por la AEDAF para las Jornadas de 13 de marzo de 2017:

Cuestión de inconstitucionalidad núm. 1012-2015, planteada por el Juzgado de lo Contencioso-Administrativo núm. 3 de Donostia-San Sebastián, en el procedimiento abreviado núm. 245/2014, Auto de 5 de febrero de 2015, Admisión a trámite: BOE de 30 de abril de 2015.

Cuestión de inconstitucionalidad núm. 232-2016, planteada por el Juzgado de lo Contencioso-Administrativo núm. 1 de Vitoria-Gasteiz, en el procedimiento abreviado núm. 82/2015, Auto de 22 de diciembre de 2015, Admisión a trámite: BOE de 26 de febrero de 2016.

Cuestión de inconstitucionalidad núm. 409-2016, planteada por Juzgado de lo Contencioso-Administrativo núm. 22 de Madrid, en el procedimiento ordinario núm. 112-2014, Auto 15 de diciembre de 2015, Admisión a trámite: BOE de 8 de marzo de 2016.

Cuestión de inconstitucionalidad núm. 6444-2015, planteada por el Juzgado de lo Contencioso-Administrativo núm. 3 de Vitoria-Gasteiz, en el procedimiento abreviado núm. 32/2015, Admisión a trámite: BOE de 5 de mayo de 2016.

Cuestión de inconstitucionalidad núm. 4864-2016, planteada por el Juzgado de lo Contencioso-Administrativo núm. 1 de Jerez de la Frontera, en el recurso contencioso-administrativo núm. 174/2015, Auto de 25 de julio de 2016, Admisión a trámite: BOE de 9 de febrero de 2017. 
teamientos ante distintos órganos judiciales, como puede comprobarse a continuación.

\section{LAS PAULATINAS APROXIMACIONES EN LA BÚSQUEDA DE SOLUCIONES JURISDICCIONALES}

La aplicación de la fórmula de cálculo de la base imponible ha sido durante muchos años y de forma continuada discutida en el seno de diferentes Comunidades Autónomas, como reflejan los siguientes casos ${ }^{8}$.

En 2010, en Cuenca, se procedió a la anulación de la liquidación complementaria practicada por un Ayuntamiento, derivada del error cometido en dicha fórmula. El recurrente aportó informes matemáticos que permitieron concluir como correcta la fórmula utilizada en su autoliquidación ${ }^{9}$, entendiéndose que el Ayuntamiento había calculado el incremento del valor del suelo en años sucesivos y no en los años pasados al aplicar el incremento sobre el valor final, el de devengo ${ }^{10}$.

Cuestión de inconstitucionalidad núm. 4865-2016, planteada por el Juzgado de lo Contencioso-Administrativo núm. 1 de Jerez de la Frontera, en el recurso ordinario núm. 4452015, Auto de extinción por desaparición sobrevenida del objeto. Admisión a trámite: $B O E$ de 9 de febrero de 2017.

Cuestión de inconstitucionalidad núm. 4866-2016, planteada por el recurso contencioso-administrativo núm. 446/2015, Auto de extinción por desaparición sobrevenida del objeto, Admisión a trámite: $B O E$ de 9 de febrero de 2017.

Cuestión de inconstitucionalidad núm. 4867-2016, planteada por Juzgado de lo Contencioso-Administrativo núm. 1 de Jerez de la Frontera, en el recurso contencioso-administrativo núm. 670-2015, Auto de extinción por desaparición sobrevenida del objeto, Admisión a trámite: $B O E$ de 9 de febrero de 2017.

Cuestión de inconstitucionalidad núm. 4868-2016, planteada por el Juzgado de lo Contencioso-Administrativo núm. 1 de Jerez de la Frontera, en el recurso contencioso-administrativo núm. 802/2014, Auto de extinción por desaparición sobrevenida del objeto, Admisión a trámite: $B O E$ de 9 de febrero de 2017.

${ }^{8}$ La doctrina se ha hecho eco de esta problemática de forma continuada. Vid. R. BRIS Gómez, «IIVTNU: Sentencia del Juzgado Contencioso-Administrativo núm. 4 de Bilbao de 18 de febrero de 2015», Quincena Fiscal, núm. 10 (2015), pp. 147-149; J. E. VARONA ALABERN, «A vueltas con la inconstitucionalidad del impuesto sobre el incremento de valor de los terrenos de naturaleza urbana», Quincena Fiscal, núm. 18 (2010), pp. 65-89, y M. B. Villaverde Gómez y A. L. Plaza VázQuez, «Impuesto sobre el incremento de los terrenos de naturaleza urbana: análisis jurisprudencial práctico», Cuadernos de Aranzadi Jurisprudencia Tributaria, núm. 38 (2005).

9 Se aportaron informes matemáticos que permitieron concluir como correcta la utilizada en su autoliquidación: plusvalía = valor final $\mathrm{x}$ núm. de años $\mathrm{x}$ coeficiente de incremento / 1+ (núm. de años x coeficiente de incremento).

${ }^{10}$ Sentencia del Juzgado de lo Contencioso-administrativo núm. 1 de Cuenca, de 21 de septiembre de 2010. 
Al respecto, el Tribunal Superior de Justicia de Castilla La Mancha estimó conforme a Derecho la valoración que había realizado el juez de instancia de la prueba documental de alcance técnico aportada por la actora en vía administrativa, posteriormente ratificada en informe pericial. Su razonamiento en la resolución impugnada estaba claramente fundamentado y apoyado en la legislación, yendo más allá de una exposición abstracta de la Administración local, que no aportaba ningún principio de prueba técnico ${ }^{11}$.

Desde Madrid se añadió que la fórmula matemática ha de ser de descuento, y no de capitalización, criticando que la fórmula matemática utilizada en la liquidación no calculaba el incremento de valor de los terrenos desde su adquisición, sino la plusvalía futura ${ }^{12}$.

En Valencia se insistió en la distinción entre los supuestos generadores de pérdidas o de ganancia cero, y los que producen un incremento, siquiera mínimo. Como el hecho imponible del IIVTNU es el incremento de valor que experimentan los terrenos urbanos, puesto de manifiesto como consecuencia de la transmisión, si ésta no pone de manifiesto ningún incremento de valor, la falta de hecho imponible impedirá la posterior determinación de la base. Dicho de otro modo, en las transmisiones con pérdidas patrimoniales, la aplicación del art 104 TRLRHL conduce a la afirmación de que no se produce hecho imponible y, por tanto, no procede la aplicación de los arts. 107 y $110.4^{13}$.

En Andalucía se dejó claro que cada vez más órganos jurisdiccionales estaban dictando sentencias entendiendo que no debería exigirse la plusvalía municipal cuando se transmitiera un inmueble con pérdidas. Se estimó que habría que probar que se había producido una reducción del valor del terreno durante el periodo de tenencia y para ello era necesario el informe técnico de un experto en la materia ${ }^{14}$.

11 STSJ de Castilla-La Mancha de 17 de abril de 2012.

12 Sentencia del Juzgado de lo Contencioso-Administrativo núm. 15 de Madrid, de 11 de noviembre de 2016. Tomando como referencia un valor final teórico o legal, al aplicarle la fórmula de descuento en función de los porcentajes de incremento o coeficientes de revalorización previstos en la Ley (art. 107), se llega a conocer el valor teórico inicial y, después, por diferencia entre uno y otro, el experimentado durante ese periodo de tenencia.

${ }^{13}$ Sentencia del Juzgado de lo Contencioso-Administrativo núm. 4 de Alicante, de 23 de febrero de 2016, en aplicación de la doctrina sentada por el TSJ de la Comunidad Valenciana de 20 de julio de 2015.

${ }^{14}$ Sentencia del Juzgado de lo Contencioso-Administrativo núm. 2 de Jaén, de 10 de marzo de 2016 (núm. 212/16, P.A. 660/15). 


\section{LAS ESPERADAS RESPUESTAS DEL TRIBUNAL CONSTITUCIONAL}

En 2017 nuestro Alto Tribunal ha tenido la oportunidad de pronunciarse sobre este espinoso asunto en varias sentencias, cuyos principales contenidos se recogen aquí de forma sintética.

La Sentencia del Tribunal Constitucional (STC) núm. 26/2017, de 16 de febrero de $2017^{15}$, ha resuelto la cuestión de inconstitucionalidad 1012/2015, planteada por el Juzgado de lo Contencioso Administrativo núm. 3 de San Sebastián, en relación con la impugnación de algunos artículos de la Norma Foral 16/1989, de 5 de julio, del Impuesto sobre el Incremento del Valor de los Terrenos de Naturaleza Urbana del Territorio Histórico de Guipúzcoa. La cuestión ha sido estimada parcialmente y se han declarado nulos los arts. 4.1, 4.2.a) y 7.4 de esta Norma Foral ${ }^{16}$.

Esta resolución, de la que ha sido ponente la Vicepresidenta del Tribunal Constitucional, doña Adela Asua Batarrita, ha sido adoptada por el Pleno por unanimidad. Los preceptos cuestionados fingen, sin admitir prueba en contrario, que por el solo hecho de haber sido titular de un terreno de naturaleza urbana durante un determinado periodo, se revela un incremento de valor (en todo caso y de forma automática). Este aumento del valor del suelo se determina mediante la aplicación automática de los coeficientes previstos en la norma al valor catastral del suelo en el momento de la transmisión, sin tener en cuenta si efectivamente el valor real se ha incrementado o no.

Como es sabido, el principio de capacidad económica no sólo se predica del sistema tributario en su conjunto, sino que debe estar presente en cada impuesto, en tanto que presupuesto mismo de la tributación. Recuerda el Tribunal que el legislador, para establecer un tributo, debe tomar en consideración actos o hechos que sean exponentes de una riqueza real o potencial. No puede crear impuestos que afecten a supuestos en los que la capacidad económica gravada por el tributo sea inexistente, irreal, virtual o ficticia.

Por ello, el Tribunal declara parcialmente inconstitucionales y nulos los preceptos impugnados «únicamente» en la medida en que someten a tri-

\footnotetext{
15 ECLI:ES:TC:2017:26 (BOE, núm. 72, 25 de marzo de 2017, pp. 22627 y ss.).

16 Se inadmite la cuestión planteada contra los arts. 107 y 110.4 TRLRHL por no ser aplicables al proceso.
} 
butación situaciones inexpresivas de capacidad económica e impiden a los sujetos pasivos acreditar que no se produjo efectivamente un incremento de valor o incluso hubo un decremento. Estos artículos de la Norma Foral son contrarios al principio de capacidad económica contemplado en el art. 31.1 de la Constitución española. No se delimitan los efectos temporales del pronunciamiento.

Por último, se indica que corresponde al legislador llevar a cabo las oportunas modificaciones o adaptaciones del régimen legal del impuesto para no someter a tributación las situaciones de inexistencia de incremento de valor de los terrenos de naturaleza urbana. Éstas se introdujeron a través del Decreto Foral-Norma de Guipúzcoa 2/2017 ${ }^{17}$, que con efectos desde el 25 de marzo 2017, establece un mecanismo para determinar con certeza la existencia o no de incremento de valor de los terrenos de naturaleza urbana y un régimen transitorio ${ }^{18}$.

En la STC núm. 37/2017, de 1 de marzo de $2017^{19}$, a raíz la cuestión de inconstitucionalidad 6444/2015, planteada por el Juzgado de lo Contencioso-Administrativo núm. 3 de Vitoria, se declaran parcialmente inconstitucionales y nulos los arts. 4.1, 4.2.a) y 7.4 de la Norma Foral 46/1989, de 19 de julio, del Impuesto sobre el Incremento del Valor de los Terrenos de Naturaleza Urbana del Territorio Histórico de Álava. También se aclara que únicamente en la medida que someten a tributación situaciones de inexistencia de incrementos de valor, en abierta contradicción con el principio de capacidad económica, tratamiento que carece de toda justificación

\footnotetext{
17 BOTHG, 3 de marzo de 2017.

18 «Gipuzkoa: se adecúa el IIVTNU a la Sentencia TCo 16-2-17». MFF, núm. 5015. EDA 2017/1003665 Lefebure-El Derecho, S. A.

El régimen transitorio diferencia los siguientes casos:

«1. Liquidaciones firmes a 25 de marzo de 2017: no proceden rectificaciones, restituciones o devoluciones basadas en la aplicación de lo dispuesto en la letra a); los procedimientos recaudatorios continuarán hasta su completa terminación y las deudas tributarias aplazadas o fraccionadas se exigirán íntegramente.

2. Liquidaciones practicadas a partir del 25 de marzo de 2017 correspondientes a devengos anteriores: se aplica lo dispuesto en la letra $a$ ).

3. Liquidaciones recurridas en reposición y pendientes de resolución a 25 de marzo de 2017: los recursos deben resolverse teniendo en cuenta lo dispuesto en la letra a).

4. Expedientes pendientes de resolución en el TEAF o en Tribunales Económico-Administrativos Municipales correspondientes a devengos anteriores a 25 de marzo de 2017. El TEAF y los Tribunales Económico-Administrativos Municipales deben:- remitir a los ayuntamientos correspondientes los expedientes para que practiquen nuevas liquidaciones teniendo en cuenta lo dispuesto en la letra a); - declarar conclusos los procedimientos, sin perjuicio de las reclamaciones que puedan interponer los interesados contra las nuevas liquidaciones que se dicten».

19 ECLI:ES:TC:2017:37 (BOE, núm. 83, 7 de abril de 2017, pp. 28509 y ss.).
} 
razonable. En definitiva, los preceptos enjuiciados son declarados inconstitucionales [arts. 4.1., 4.2.a) y 7.4] por no haber previsto excluir del tributo a las situaciones inexpresivas de capacidad económica — en el caso de inexistencia de incremento de valor-. Y es que con una metodología que tiene en cuenta solamente el valor catastral del suelo del inmueble en el momento de la venta y el número de años que éste haya estado en manos del propietario, siempre existen plusvalías, independientemente de que su valor no se haya incrementado en realidad.

Se ha abordado diligentemente la adaptación normativa a través del Decreto Normativo de Urgencia Fiscal 3/2017, del Consejo de Gobierno Foral de 28 de marzo, relacionado con el Impuesto sobre el Incremento del Valor de los Terrenos de Naturaleza Urbana (Álava) y el Decreto ForalNorma 2/2017, de 28 de marzo, por el que se modifica el Impuesto sobre el Incremento del Valor de los Terrenos de Naturaleza Urbana ${ }^{20}$.

A comienzos del mes de mayo de 2017 se conocen dos sentencias más del Tribunal Constitucional sobre el IIVTNU. La primera es la STC núm. 57/2017, de 11 de mayo de $2017^{21}$, en la que el Pleno inadmite la cuestión de inconstitucionalidad 409/2016, promovida por el Juzgado núm. 22 de Madrid, en relación con los arts. 107 y 110.4. TRLRHL, por inadecuada formulación del juicio de relevancia. Como se explica en el fundamento jurídico primero, la pretensión deducida por el demandante se dirigía a cuestionar el valor catastral asignado a los terrenos a efectos del impuesto sobre bienes inmuebles, por mucho que dicho valor hubiese servido luego para el cálculo de la base imponible del impuesto sobre el incremento del valor de los terrenos de naturaleza urbana. Así, el juicio de relevancia - al requerir que la decisión del proceso a quo dependa de la validez de la norma cuestionada (art. 35.2 LOTC)_ impide que la cuestión de inconstitucionalidad quede desvirtuada por un uso no acomodado a su naturaleza y finalidad.

Según la Abogada del Estado, si la parte actora considera que los valores catastrales estaban mal determinados, esto no es un problema de capacidad económica, sino de articular los mecanismos de impugnación previstos en la normativa vigente contra esos valores ${ }^{22}$. El Tribunal observa que

${ }^{20}$ AEDAF. Revista Interactiva de Actualidad, núm. 16 (2017).

${ }^{21}$ ECLI:ES:TC:2017:57 (BOE, núm. 142, 15 de junio de 2017, pp. 49550 y ss.).

22 Subraya también la Abogada del Estado que, en la redacción dada por la Ley 51/2002 al art. 107 LHL, la base imponible estará constituida por el «incremento del valor de los terrenos», desapareciendo el término «real» que adjetivaba al incremento y que el fundamento del impuesto es gravar la riqueza potencial experimentada por la acción urbanística 
el auto de planteamiento proyecta la duda de constitucionalidad formulada sobre unas normas [los arts. 107.2.a) y 110.4 LRHL] que no son las que constituyen el objeto directo de la queja de la parte actora en el proceso a quo (el art. 23.2 de la Ley del Catastro Inmobiliario, porque el valor catastral de los terrenos es superior - en un trescientos por cien- al fijado por la Comunidad de Madrid a efectos de los impuestos sobre transmisiones patrimoniales y actos jurídicos documentos y sobre sucesiones y donaciones, cuando, de conformidad con este artículo, el valor catastral de los inmuebles no podrá superar el valor de mercado $\left.{ }^{23}\right)$. Entiende el Tribunal Constitucional que analizar si el valor catastral que ha servido de base a las liquidaciones del Impuesto sobre el Incremento de Valor de los Terrenos de Naturaleza Urbana se ha ajustado en su determinación a las reglas y límites previstos en la normativa reguladora del Catastro inmobiliario, plantea, en principio, sólo un problema de legalidad ordinaria.

En la STC núm. 59/2017, de 11 de mayo de 2017²4, fruto de la cuestión de inconstitucionalidad 4864/2016, el Pleno acuerda por unanimidad declarar la nulidad parcial del art. 107 LRHL y del 110.4 LRHL por conexión con él. De nuevo, únicamente por gravar situaciones que no expresan capacidad económica e impedir a los sujetos pasivos acreditarlo.

En las sentencias anteriormente reseñadas, el Tribunal Constitucional no había examinado la inconstitucionalidad de los arts. 107 y 110.4. TRLRHL por no entenderlo relevante para la adopción del fallo. Sin embargo,

del municipio, devolviendo a la colectividad parte del beneficio obtenido con fundamento en el art. 47 CE. Por su parte, la Fiscal General del Estado considera que cabe descartar la posible inconstitucionalidad de los arts. 107 y 110.4 LHL sobre la base de criterios extrafiscales. En este sentido, subraya que el Impuesto sobre el Incremento del Valor de los Terrenos de Naturaleza Urbana es una fuente de ingresos de los municipios, esto es, un instrumento que contribuye a procurar la autonomía financiera de los entes locales (art. 142 CE). Pues bien, el método objetivo de cuantificación del incremento (la simplicidad del tributo) no sólo ha buscado, a su juicio, la eficacia en la gestión y en la recaudación (evita gastos costosos y facilita la lucha contra el fraude fiscal), sino que también ha permitido proporcionar al obligado tributario el cumplimiento de sus deberes tributarios. Además, el fundamento de este impuesto se encuentra en el art. 47.2 CE (revertir a la comunidad los beneficios que deriva de la actuación pública en el bien objeto de transmisión fruto de la actividad urbanizadora).

${ }^{23} \mathrm{Y}$ aunque para fijar el valor del terreno el art. 107.2.a) LHL se remita al valor que tenga determinado en el momento del devengo a efectos del Impuesto sobre Bienes Inmuebles, esto es, al «valor catastral de los bienes inmuebles» que se determinará «conforme a lo dispuesto en las normas reguladoras del Catastro Inmobiliario» (art. 65 LHL) y, concretamente, de acuerdo con los criterios y límites previstos en el Real Decreto Legislativo 1/2004, de 5 de marzo, por el que se aprueba el texto refundido de la Ley del Catastro Inmobiliario, lo cierto es que ninguna consideración realiza al respecto el órgano judicial.

${ }^{24}$ ECLI:ES:TC:2017:59 (BOE, núm. 142, 15 de junio de 2017, pp. 49581 y ss.). 
en ésta, con ocasión de una de las cinco cuestiones planteadas por el Juzgado Contencioso-Administrativo núm. 1 de Jerez de la Frontera, el Tribunal Constitucional ahora puede pronunciarse expresamente sobre los arts. 107.1., 107.2.a) y 110.4. del Real Decreto 2/2004, de 5 de marzo, por el que se aprueba el Texto Refundido de la Ley Reguladora de las Haciendas Locales (TRLRHL). Dado que la redacción de los apartados de los preceptos cuestionados en el presente caso es idéntica a la de las normas forales previamente declaradas inconstitucionales y dado que las dudas expuestas por el órgano judicial también son idénticas a las ya analizadas en las Sentencias citadas, se declara igualmente su inconstitucionalidad y nulidad «únicamente en la medida que someten a tributación situaciones de inexistencia de incremento de valor».

El Tribunal acepta el razonamiento del Fiscal General del Estado y, aunque el órgano judicial solamente ha puesto en duda la constitucionalidad y nulidad del art. 107 TRLRHL, la extiende a su art. 110.4, debido a la conexión con los arts. 107.1, 107.2.a) TRLRHL, ya que no puede explicarse el resultado sin las normas de valoración ${ }^{25}$. Deja fuera las letras $b$ ), c) y d) del apartado 2 del art. 107 TRLRHL, aunque el órgano judicial se refería a la totalidad del precepto, porque la liquidación impugnada en el proceso a quo deriva de la transmisión onerosa de unos terrenos ${ }^{26}$.

Concluye que la regulación vigente vulnera el principio constitucional de capacidad económica porque la mera titularidad de un terreno de naturaleza urbana lleva vinculada, «como consecuencia inseparable e irrefutable», un incremento de valor sometido a tributación. $\mathrm{Al}$ valor del terreno a efectos del Impuesto sobre Bienes Inmuebles en el momento de la transmisión se aplica un porcentaje fijo por cada año de tenencia, con independencia no sólo de la cantidad real del incremento, sino de su propia existencia. El Alto Tribunal declara la inconstitucionalidad de esta Ley sólo en la medida en la que no ha previsto excluir del tributo las situaciones inex-

25 «Aunque en el posterior auto de planteamiento no exista referencia alguna al citado art. 110.4, el art. 39.1 LOTC permite extender la declaración de inconstitucionalidad, "por conexión o consecuencia", a otros preceptos de la misma Ley, lo que debería producirse en este caso al existir una íntima conexión entre las reglas de determinación de la base imponible y ese art. 110.4, que impide a las corporaciones locales prescindir de la regla de cálculo legalmente establecida, aun cuando se haya producido una minusvaloración del valor del terreno en el momento de la transmisión».

${ }^{26}$ En ellas se acogen las reglas para la determinación del valor de terreno en la constitución y transmisión de derechos reales de goce limitativos del dominio [letra $b$ )]; en la constitución o transmisión del derecho a elevar una o más plantas sobre un edificio o terreno, o del derecho de realizar la construcción bajo suelo sin implicar la existencia de un derecho real de superficie [letra $c)$ ], y en las expropiaciones forzosas [letra $d$ )]. 
presivas de capacidad económica. El legislador debe llevar a cabo modificaciones que permitan arbitrar el modo de «no someter a tributación las situaciones de inexistencia de incremento de valor de los terrenos de naturaleza urbana».

En palabras del Tribunal, extraídas del fundamento jurídico tercero de esta Sentencia: «parece claro que la circunstancia de que el nacimiento de la obligación tributaria se hiciese depender, entonces y también ahora, de la transmisión de un terreno, «podría ser una condición necesaria en la configuración del tributo, pero, en modo alguno, puede erigirse en una condición suficiente en un tributo cuyo objeto es el "incremento de valor" de un terreno. Al hecho de esa transmisión hay que añadir, por tanto, la necesaria materialización de un incremento de valor del terreno, exponente de una capacidad económica real o, por lo menos, potencial. Sin embargo, cuando no se ha producido ese incremento en el valor del terreno transmitido, la capacidad económica pretendidamente gravada deja de ser potencial para convertirse en irreal o ficticia, violándose con ello el principio de capacidad económica (art. 31.1 CE)» (STC 37/2017, FJ 3). [...] Los preceptos cuestionados de la Ley reguladora de haciendas locales en los supuestos de no incremento, o incluso de decremento, en el valor de los terrenos de naturaleza urbana, gravan una renta ficticia en la medida en que, al imponer a los sujetos pasivos del impuesto la obligación de soportar la misma carga tributaria que corresponde a las situaciones de incrementos derivados del paso del tiempo, está sometiendo a tributación situaciones de hecho inexpresivas de capacidad económica, lo que contradice frontalmente el principio de capacidad económica que garantiza el art. 31.1 CE. En consecuencia, los preceptos cuestionados deben ser declarados inconstitucionales, aunque sólo en la medida en que no han previsto excluir del tributo las situaciones inexpresivas de capacidad económica por inexistencia de incrementos de valor (SSTC 26/2017, FJ 3; y 37/2017, FJ 3)».

Desde la Abogacía del Estado se recuerda que, según el art. 47 de la Constitución, la comunidad participará en las plusvalías que genera la acción urbanística de los entes públicos y que cuando los precios de los inmuebles subieron de manera descontrolada, sólo se tributaba por el valor catastral y no el de mercado, subrayando la existencia de dos medidas previstas en el TRLRHL con las que se pudo hacer frente a la crisis inmobiliaria (la reducción del valor catastral en un 60 por 100 durante los cinco años siguientes a su revisión y la actualización, incluso a la baja, de los valores catastrales). Sin embargo, estima el Tribunal Constitucional que 
con estas medidas lo único que se consigue es reducir el importe del IIVT$\mathrm{NU}$ al minorar la base imponible, pero no evitar que haya conflicto con el principio de capacidad económica.

En definitiva, no se impide el establecimiento por el legislador de impuestos que graven el incremento del valor de los terrenos de naturaleza urbana, siempre y cuando su configuración respete el principio de capacidad económica.

\section{POSIBLES VÍAS DE IMPUGNACIÓN EN LA ACTUALIDAD}

Se ha estimado que número de viviendas sobre las que se podría solicitar la devolución del pago de la plusvalía municipal, al haberse transmitido mediante operaciones de compraventa, donación, permuta o herencia, por un valor inferior al de adquisición, es de 550.000 aproximadamente en los últimos cuatro años no prescritos ${ }^{27}$.

Con carácter general, en cuanto al alcance de las sentencias declaratorias de inconstitucionalidad, debe estarse al art. 40 de la Ley Orgánica núm. 2/1979, de 3 de octubre, del Tribunal Constitucional ${ }^{28}$.

En cada caso concreto, deberá contemplarse si el Ayuntamiento correspondiente prevé en sus Ordenanzas Fiscales reguladoras del impuesto la declaración y posterior liquidación o la autoliquidación. Dentro de ese sistema de declaración y posterior liquidación habrá que diferenciar entre liquidaciones que aún no hayan adquirido firmeza frente a aquellas firmes ${ }^{29}$.

Sobre las posibles vías de impugnación de las correspondientes liquidaciones o autoliquidaciones del IIVTNU, tras las SSTC, se ha escrito

${ }^{27}$ Calculado por Tinsa a partir de sus estadísticas de evolución del precio de la vivienda (índice IMIE) y de datos del Ministerio de Fomento y del Colegio de Registradores de la Propiedad. La estimación también tiene en cuenta el periodo medio que los inmuebles han estado en manos de sus propietarios para las transmisiones desde 2014 a 2016. Vid. Newsletter Iustel, 18 de mayo de 2017.

${ }^{28}$ «Las sentencias declaratorias de la inconstitucionalidad de Leyes, disposiciones o actos con fuerza de Ley no permitirán revisar procesos fenecidos mediante sentencia con fuerza de cosa juzgada en los que se haya hecho aplicación de las Leyes, disposiciones o actos inconstitucionales [...]. En todo caso, la jurisprudencia de los tribunales de justicia recaída sobre leyes, disposiciones o actos enjuiciados por el Tribunal Constitucional habrá de entenderse corregida por la doctrina derivada de las sentencias y autos que resuelvan los procesos constitucionales».

${ }^{29}$ B. Sesma SÁnchez, La nulidad de las liquidaciones tributarias, Cizur Menor, Aranzadi, 2017, p. 235. 
mucho $^{30}$. Cabe considerar la pertinencia del recurso de reposición contra la liquidación del IIVTNU y la solicitud de rectificación de autoliquidación del IIVTNU con devolución de ingresos indebidos.

Interesa destacar que recientemente la Sentencia del Juzgado de lo Contencioso-administrativo núm. 2 de La Coruña, de 30 de junio de 2017, ha interpretado la STC de 11 de mayo de 2017 que declaró inconstitucionales y nulos y expulsó del ordenamiento jurídico los arts. 107.1, 107.2 a) y 110.4 de la Ley de Haciendas Locales. Concluye que no resulta necesario probar que no hubo plusvalía para obtener la nulidad de las autoliquidaciones (o, en su caso, liquidaciones), porque «la declaración de inconstitucionalidad de la disposición pero también la nulidad de la norma es incondicionada, y no se limita tampoco a unos concretos escenarios en los que el cálculo de la base imponible determine la inexistencia de plusvalía» ${ }^{31}$.

La Sentencia 123/2017 del Juzgado de lo Contencioso Administrativo núm. 1 de Santander, de 14 de junio de 2017, con respecto a la misma STC, critica que el inciso (que declara la inconstitucionalidad «pero únicamente en la medida que someten a tributación situaciones de inexistencia de incrementos de valor») ha motivado distintas interpretaciones en tanto en cuanto el legislador no dicte una nueva norma. Entre ellas, incluye la pretendida por el Ayuntamiento de que la inconstitucionalidad declarada sería, en alguna forma, condicionada, de modo que si hay incremento, esos preceptos ya no son inconstitucionales y deben aplicarse. Ante tal pretensión, afirma de manera contundente en su fundamento jurídico segundo: «Es claro que el TC no ha dictado una sentencia interpretativa, en la cual, declara que un precepto no es inconstitucional si se hace una interpretación determinada. Esta vía era la que seguíamos numerosos juzgados, permitiendo la práctica de prueba en contrario en juicio, de modo que, si se acreditaba la ausencia de incremento de valor del terreno, no había hecho imponible del art. 104 TRLHL y con ello, sencillamente, no cabía aplicar el cálculo de la base imponible del art. 107 mediante el sistema de gestión del art. 110 desarrollado por cada Ordenanza. El TC deja claro que el impuesto, en sí mismo, no es inconstitucional y con ello, no se anula el

30 J. M. SalCedo Benavente, Guía práctica para impugnar la plusvalía municipal tras la declaración de inconstitucionalidad, AEDAF, 2017. AEDAF. Revista Interactiva de Actualidad (RIA), núm. 19, 16 de mayo de 2017. Esta obra analiza las posibilidades de solicitar la devolución del impuesto pagado en aquellos casos en los que se ha producido una venta o transmisión a pérdidas, así como las pruebas admisibles para justificar la pérdida.

${ }^{31}$ Referencia tomada de AEDAF, Revista Interactiva de Actualidad (RIA), núm. 28, 17 de julio de 2017. 
art. 104. Pero en relación con el resto de preceptos cuestionados, su pronunciamiento es claro, se declaran nulos y se expulsan del ordenamiento jurídico ex origine (F.V. del fallo constitucional). Y además, declara esa inconstitucionalidad al entender que no es posible la interpretación conforme que se venía haciendo, pues ni los ayuntamientos por vía de gestión ni el juez, en el proceso, pueden decidir cuándo hay o no hay incremento, en qué consiste y cómo se acredita esa circunstancia».

En consecuencia, hay pues que respetar la libertad de configuración del legislador. Mientras tanto, la Administración debe ser consciente de los riesgos que asume. Sobre este punto, añade, en su fundamento jurídico quinto, que «si bien es cierto que el acto de gestión tributaria recurrido era ajustado a la normativa vigente al tiempo de citarlo y ha sido preciso un pronunciamiento posterior del TC sobre esa ley, que la administración estaba obligada a acatar, también es cierto que tras el dictado de la sentencia no se ha producido el allanamiento en la vista al defenderse una interpretación no acogida. Esto, lleva a la imposición de costas en el asunto» —a la parte demandada-.

Por último, no está de más recordar que la Subdirección General de Tributos Locales, en la consulta vinculante V0549-17, de 2 de marzo de 2017, ha reconocido la legitimación activa del adquirente para interponer recursos y reclamaciones por ser titular de un interés legítimo y directo como consecuencia del pago de la deuda tributaria que resulta de la liquidación girada por el Ayuntamiento ${ }^{32}$.

\section{PROPUESTAS DE LEGE FERENDA}

Como ha dicho el Tribunal Constitucional en el fundamento jurídico tercero de la Sentencia núm. 59/2017, «la crisis económica ha convertido lo que podía ser un efecto aislado - la inexistencia de incrementos o la

32 M. NAVARRo EgEA, «Si el comprador asume el pago del IIVTNU según lo estipulado en el contrato de compraventa, ¿puede recurrir la liquidación girada por el Ayuntamiento? A propósito de consulta vinculante de la DGT V0549-17, de 2 de marzo de 2017», Revista Interactiva de Actualidad (RIA), núm. 27, 10 de julio de 2017. La interpretación pro actione se sostiene porque «el órgano consultivo articula su respuesta sobre dos consideraciones: 1. ${ }^{a}$ el deslinde de la posición del comprador que asume el pago respecto a la Administración a efectos de interponer recurso o reclamación; 2. ${ }^{a}$ el tenor literal del art. 14.2 del Texto Refundido de la Ley Reguladora de las Haciendas Locales (Real Decreto Legislativo 2/2004) y de la disp. adic. 4. ${ }^{a}$ de la LGT (Ley 58/2003)». 
generación de decrementos- en un efecto generalizado, al que necesariamente la regulación normativa del impuesto debe atender».

El legislador estatal, a la hora de introducir los cambios necesarios en la Ley Reguladora de las Haciendas Locales ${ }^{33}$, habría de tener en cuenta los avances ya recogidos en la normativa foral y las propuestas formuladas por la Federación Española de Municipios y Provincias (FEMP).

Interesa prestar atención a la regulación del IIVTNU recientemente adoptada en Vizcaya para lograr su adecuación a lo dispuesto jurisprudencialmente en las SSTC de 1 de marzo de 2017 y de 16 de febrero de 2017 - recaídas sobre la normativa de los otros dos territorios forales- ${ }^{34}$.

Desde el 22 de junio de 2017, se arbitra un nuevo mecanismo para determinar con certeza la existencia o no del incremento de valor de los terrenos, sometiendo a gravamen únicamente supuestos en los que éste exista. Además, para mayor seguridad jurídica de los contribuyentes, se incorpora un régimen transitorio, tomando en consideración la citada fecha.

La regla general para la determinación del incremento de valor de los terrenos de naturaleza urbana, contenida en el apartado a), indica que la existencia del incremento se determina comparando el valor de adquisición de la propiedad o de la constitución o adquisición del derecho real de goce limitativo del dominio, y su valor de transmisión en las respectivas fechas. Estos valores son los que consten en los correspondientes documentos acreditativos de los títulos correspondientes, sin añadir gastos, mejoras u otros conceptos y sin actualizarlos.

Se prevén algunos supuestos específicos: si no se diferencia de forma expresa el valor atribuible a la construcción y al suelo, debe tomarse como referencia la proporción del valor catastral del suelo y el valor catastral de la construcción respecto al valor catastral vigente al devengo del impuesto; si el valor catastral del suelo y la construcción no puede desglosarse, se puede aplicar el mismo con una reducción del 60 por 100.

33 B. Moreno Serrano, «Plusvalía: una agonía que se podía haber evitado», El Consultor de los Ayuntamientos, núm. 12, 15 de junio a 14 de julio de 2017, p. 1555. A. B. PrósPER Almagro, «IIVTNU: hacia una inaplazable reforma de gran calado», Quincena Fiscal, núm. 21 (2014) (BIB 2014\4258). D. Marín BarnueVo-FABO, «La necesaria modificación del impuesto municipal sobre el incremento de valor de los terrenos», Boletín de Noticias del Instituto de Derecho Local de la UAM, núm. 45 (2013). C. FAYOS, «La necesaria reforma del Impuesto sobre el Incremento de Valor de los Terrenos de Naturaleza Urbana», Actualidad Jurídica Aranzadi, núm. 867 (2013) (BIB 2013\1625).

${ }^{34}$ NF Bizkaia 9/1989 disp. adic. 1. ${ }^{a}$ redacción DFN Bizkaia 3/2017, BOTHB 22 de junio de 2017 y DFN Bizkaia 3/2017 disp. trans. única, BOTHB 22 de junio de 2017. «Bizkaia: se adecúa el IIVTNU a lo dispuesto jurisprudencialmente sobre la normativa de los otros dos territorios forales». MFF núm. 5015. EDA 2017/506095. Lefebvre-El Derecho, S. A. 
Y si no existe incremento de valor, por un lado, a efectos de futuras transmisiones, se deben considerar los valores correspondientes a los momentos de adquisición y transmisión del terreno por parte del futuro transmitente; por otro lado, se mantiene la obligación formal establecida por el art. 7 de la Norma Foral 8/1989 de presentar la declaración del Impuesto $^{35}$.

Por su parte, la FEMP ha remitido al Ministerio de Hacienda y Función Pública algunas propuestas para modificar el IIVTNU, aprobadas por su Junta de Gobierno el 30 de mayo de $2017^{36}$, solicitando que dicho Ministerio publique una nota aclaratoria sobre el procedimiento de actuación a seguir por los Ayuntamientos hasta que se apruebe la reforma, dada la inseguridad jurídica que afecta tanto a los contribuyentes como a las propias Corporaciones Municipales.

La FEMP propone incorporar en la determinación de la base imponible los coeficientes de variación del mercado inmobiliario del suelo para cada año, a partir de una fuente oficial y con actualización anual por Ley de Presupuestos, manteniendo la referencia al valor catastral. Para acreditar el incremento real del valor del terreno entiende que podrá seguirse el procedimiento del art. 57 de la Ley General Tributaria o cualquier otro que ofrezca garantías jurídicas para las partes. Además, solicita suprimir la exención del pago del impuesto en las plusvalías inferiores al año.

De plantearse una reforma integral del impuesto, señala la FEMP que la nueva base habría de tener en cuenta el incremento real de valor (diferencia entre el valor de transmisión menos el valor de adquisición), extendiendo el incremento también al valor de la construcción y a los inmuebles rústicos. En todo caso, la cuota del impuesto debería ser deducible en los impuestos estatales, para evitar problemas de doble imposición.

Por último, esta Federación demanda una compensación a los Ayuntamientos que a la fecha de publicación de la Sentencia tengan aprobado el Impuesto, por la pérdida de recaudación derivada de la aplicación de la Sentencia. Como es bien sabido, los Ayuntamientos durante los años de crisis económica se han estado apoyando en gran medida en la recaudación de este impuesto, sobre todo, en las grandes ciudades.

35 En los mismos términos que en la NF Gipuzkoa 16/1989.

${ }^{36} \mathrm{Cfr}$. http://www.femp.es/comunicacion/noticias/propuesta-de-la-femp-al-impuesto-sobre -plusvalias En la Junta de Gobierno de 18 de julio de 2017, se reitera la urgencia de la modificación legislativa para despejar la inseguridad jurídica, una vez que Hacienda ya tiene su propuesta. http://www.femp.es/comunicacion/noticias/la-femp-exige-celeridad-en-la-modi ficacion-del-impuesto-de-plusvalia-una-vez [última visita el 7 de agosto de 2017]. 